\title{
Bilateral testicular torsion in a 36-week neonate
}

\author{
Michael J H Clarke, ${ }^{1}$ Samuel Crocker, ${ }^{1}$ David G Bartle, ${ }^{2}$ John Apsey ${ }^{1}$
}

${ }^{1}$ Royal Devon and Exeter NHS Foundation Trust, Exeter, UK ${ }^{2}$ Department of Child and Women's Health, Royal Devon and Exeter Hospital, Exeter, UK

Correspondence to Dr Michael J H Clarke, mjh.clarke@doctors.org.uk

Accepted 19 January 2018
Check for updates

To cite: Clarke MJH, Crocker S, Bartle DG, et al. BMJ Case Rep Published Online First: [please include Day Month Year]. doi:10.1136/bcr-2017223093

\section{SUMMARY}

A male neonate born after uncomplicated vaginal delivery at 36 weeks' gestation was noted to have large and firm testicles bilaterally on routine examination. A testicular ultrasound scan was subsequently organised that showed detailed appearances consistent with bilateral testicular torsion. This was thought to have taken place antenatally and as such was unfortunately not suitable for intervention. The patient was therefore managed conservatively with the testicles left to involute naturally. He was started on testosterone replacement therapy after follow-up when gonadotrophin levels were found to be raised and testosterone low (suggesting absent testicular function) and will be closely followed up regarding his future development which is normal to this point.

\section{BACKGROUND}

Neonatal testicular torsion is a well-described although unusual complication of the neonatal period and is one that can have severe outcomes for neonates if missed in terms of potential testicular loss. ${ }^{12}$

The vast majority of neonatal torsions (defined as occurring at $<30$ days of age) are unilateral ${ }^{34}$ and have a different pathogenesis to torsion in older children/adults in that they tend to involve the entire testicle including tunica vaginalis twisting on the spermatic cord as opposed to intravaginal torsion inside the tunica as typically seen later on. ${ }^{2}$

Neonatal torsion is almost always unilateral and only a few cases of bilateral in utero torsion as in this case have been described. ${ }^{25}$ Commonly unilateral torsion or 'missed testis' suggestive of early in utero torsion may be noted, but for a baby to be born and by a few hours of age have irreversible torsion of both testicles simultaneously is very rare. $^{245}$

\section{CASE PRESENTATION}

A macrosomic male infant (birth weight $4070 \mathrm{~g}$ ) was born via spontaneous vaginal delivery at 36 weeks' gestation to a gestational diabetic mother. He was born with his neck wrapped by the umbilical cord and required some inflation breaths at birth but no further assistance. Maternal gestational diabetes mellitus was managed with diet only, and the pregnancy was otherwise normal save for hypertension 3 days antenatally, managed with labetalol. All antenatal scans were normal as was routine serology. There was no other significant history of note, in particular, no family history of testicular torsion or other genitourinary problems.
Both parents and the infant's male sibling were otherwise healthy.

At approximately 1 hour of age, the patient developed tachypnoea with intermittent grunting. His respiratory distress worsened, and he was therefore admitted to the neonatal unit (NNU) at 7 hours of age for respiratory support. On admission he was noted to be hypothermic and hypoglycaemic which were managed with placement in an incubator and top up feeds of formula, respectively. He was also found to be polycythaemic (haemoglobin $228 \mathrm{~g} / \mathrm{L}$, age-adjusted normal range $135-195 \mathrm{~g} / \mathrm{L}$ ), and he was managed presumptively for sepsis with antibiotics for 48 hours until blood cultures were reported as clear and serial inflammatory markers were negative (C reactive protein $<1 \mathrm{mg} / \mathrm{L}$ throughout). Neonatal jaundice was managed with a short period of phototherapy and his mother was supported to establish full breast feeding.

The patient was examined several times by doctors of varying seniorities and other health professionals during his first days of life on NNU. Various notes were made with regards to a slightly abnormal testicular examination at different times, including a finding of bilaterally enlarged and firm testes of uncertain significance. However, on each occasion, torsion was reported as being unlikely as no particular features of concern for this were found.

Due to the continuing uncertainty of the diagnosis, a testicular ultrasound was subsequently arranged and was performed on day 3 of life. This was sadly consistent with bilateral testicular torsion (see figures 1-3). Both testes were oedematous and irregular in outline (figure 1), with epididymal hypoechogenicity and no visible vascular flow in either testis (figure 2). There was no evidence of herniation with a normal inguinal canal although some thickening of surrounding tunica was present (figure 3). The patient had never showed signs of distress postnatally which may have indicated acute torsion.

Unfortunately, the opinion from our paediatric urology specialist colleagues was that this was likely to have been an in utero event and as such was not amenable to surgical intervention.

\section{INVESTIGATIONS}

Testicular ultrasound, see figures 1-3.

At 6 weeks, blood tests and clinical findings were consistent with testicular failure:

- Follicle-stimulating hormone (FSH) $94 \mathrm{mIU} /$ $\mathrm{mL}(1.5-12 \mathrm{mIU} / \mathrm{mL})$.

- Luteinising hormone (LH) $74.5 \mathrm{mIU} / \mathrm{mL}$ (1.7$8.6 \mathrm{mIU} / \mathrm{mL})$. 


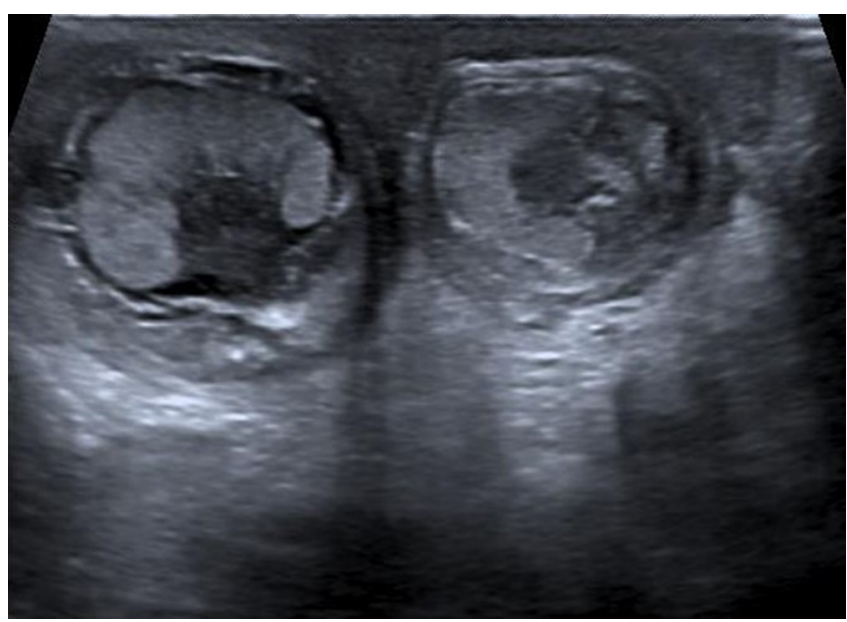

Figure 1 Bilaterally irregular and oedematous testes with a horseshoe-shaped appearance.

- Testosterone $1.0 \mathrm{nmol} / \mathrm{L}(<6.0 \mathrm{nmol} / \mathrm{L})$.

- Shrunken testicles.

\section{DIFFERENTIAL DIAGNOSIS}

Diagnosis unclear-thought to be possibly related to 'macrosomia or birth trauma'.

\section{TREATMENT}

As above, deemed not suitable for intervention, therefore managed conservatively.

\section{OUTCOME AND FOLLOW-UP}

Unfortunately, the case was not felt to be amenable for surgical intervention due to likely in utero nature of the event and time passed prior to discovery-testes non-salvageable bilaterally. Therefore, managed conservatively and testes left to involute naturally.

When reviewed in clinic at 6 weeks of age, gonadotrophins (FSH and $\mathrm{LH}$ ) were raised and testosterone was low suggestive of testicular failure. The patient was therefore started on low-dose testosterone replacement therapy and will be regularly reviewed regarding the future development. He will be considered for topical testosterone therapy to his phallus to assist

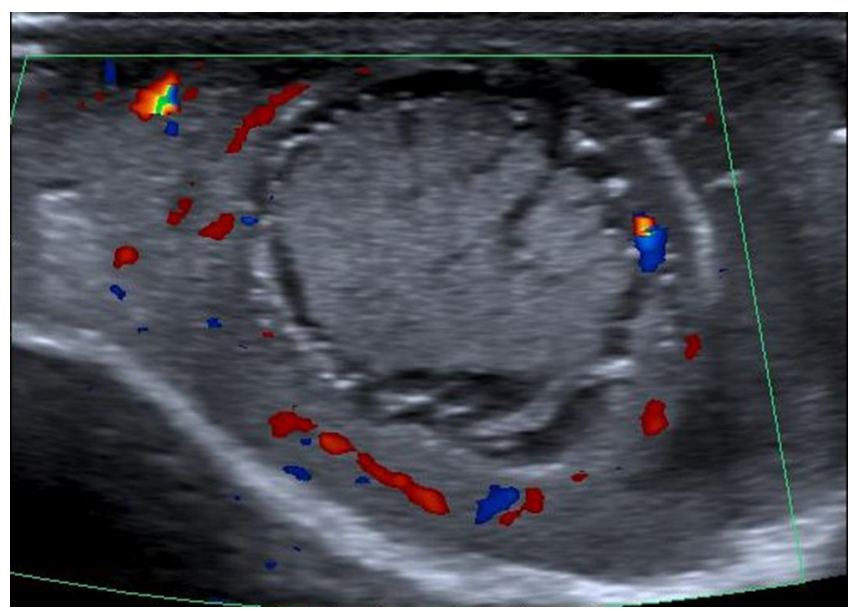

Figure 2 Lack of vascular flow detailed within right testis (also seen on the left).

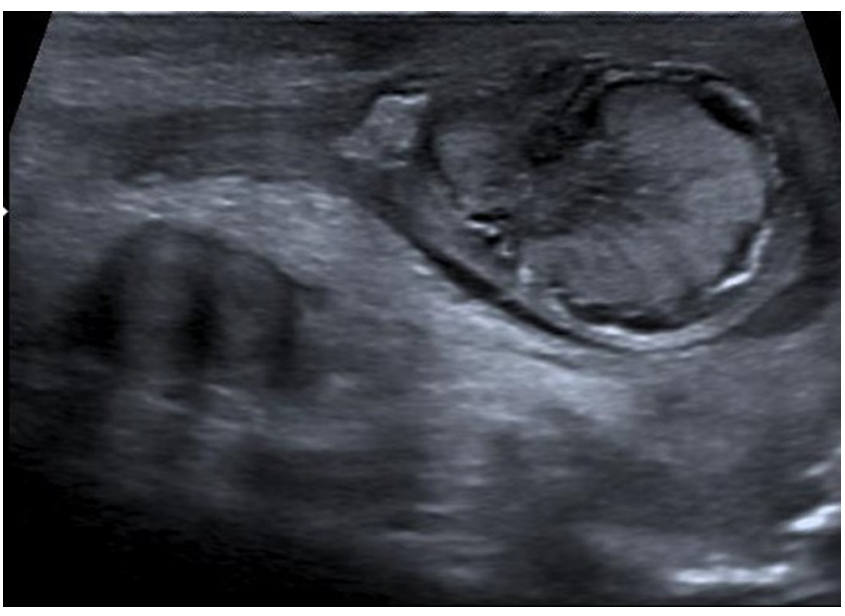

Figure 3 Patent inguinal canal seen with no hernias and thickening of the surrounding tunica.

development. His development is currently within normal limits at 3 months of age.

It is very important to bear the huge psychosocial impacts that this kind of situation can have in mind when seeing patientsoften our view as healthcare professionals does not fully tally with those of our patients. This is particularly true when being given some potentially devastating news as here, which may not have yet had time to fully sink in and can adversely impact not only patients but also their relatives and wider associates.

\section{DISCUSSION}

This case adds to the field of knowledge of the very rare case of bilateral testicular torsion in the neonatal period. Although neonatal torsion is a well-described complication in the neonatal period with an incidence of approximately 6.1/100 000 births in the $\mathrm{UK},{ }^{1}$ this is almost always unilateral and the pathogenesis is somewhat different from those in older children and adolescents. ${ }^{2}$ Neonatal torsion represents approximately $10 \%-12 \%$ of paediatric testicular torsions ${ }^{3}$ and approximately $70 \%$ of torsions are thought to be present at delivery with $30 \%$ arising within the first month.

The case of torsion reported here was likely an in utero event and as such not amenable to intervention even if it had been discovered early. However, it is important to consider the rare possibility of torsion in neonates with even atypical findings of 'abnormal testes' on examination and the need for prompt investigation and escalation. This low index of suspicion is key as potentially with emergent surgery, it may be possible to salvage the testicle(s) provided recognition is prompt, although quoted rates of success of such surgery vary significantly from $0 \%$ in some case series to $100 \%$ in others ${ }^{5}$ - generally such series have been small in number and vary in how they classify/group cases. Clinicians must also be wary as there are sometimes very few clinical signs of torsion. Traditionally, there has been thought to be no role for imaging such as ultrasound in the diagnosis of suspected torsion and surgical exploration has been held as the gold standard of management, although recently it has been increasingly used with increased sensitivity reported. ${ }^{6-8}$

Bilateral perinatal torsions specifically are commonly classified according to when the testes were thought to have torted relative to one another-synchronous, metasynchronous or asynchronous torsion. ${ }^{9}$ Synchronous torsion is thought to represent approximately two-thirds of perinatal torsions of those that have been reported, however, metasynchronous and asynchronous torsions do occur and hence it is important to beware the risk of subsequent 
torsion of the other testis. ${ }^{10}$ Clinical examination is unreliable at determining the status of the contralateral testis and hence contralateral testis exploration \pm fixation is often recommended. ${ }^{10}$ There is some evidence that delaying operative intervention in suspected unilateral torsion may confer increased risks to the otherwise unaffected contralateral side and therefore some series have recommended emergent surgery for suspected cases of unilateral perinatal torsion even where the chance of salvage of the involved testis is thought to be small. ${ }^{9-11}$ Of note, one series suggested that in cases of asynchronous torsion, the right side is more likely to be affected first; however, to date no conclusive explanation for this has been forthcoming. ${ }^{8}$

Success rates of emergency surgery in cases of suspected in utero torsion (ie, where there has never been a normal testicular examination and no acute change has been identified) are $\operatorname{low}^{15}$ and given the potential risks of surgery careful consideration of the risks and benefits need to be made prior to intervening as was done here-some authors have advocated conservative management in many cases especially if torsion is thought to have occurred antenatally, ${ }^{12}$ potentially with non-urgent surgery to confirm the diagnosis and perform orchidectomy later on. ${ }^{12}$ Others, however, still recommend emergent surgery in all cases, with debate as to whether orchidopexy or orchidectomy is more appropriate. ${ }^{813-15}$

One of the more extensive review articles therefore (RiazUl-Haq et $a l)^{2}$ concluded that emergent exploration in cases of confirmed or doubtful torsion (without prior imaging) with exploration of the contralateral side if unilateral was an optimal management strategy, ${ }^{2}$ and other studies have come to similar conclusions. $^{89}$ In this case, however, expert opinion from our paediatric urology colleagues disagreed with this view and felt that a 'watch-and-wait' approach was more suitable given the potential risks of surgery and limited benefits; on review at 6 weeks of age, the patients testes were both correctly sited and were already

\section{Learning points}

- Testicular torsion is a rare presentation in the neonatal period but is potentially devastating if missed.

- Most neonatal torsions are unilateral although bilateral torsions have been described.

- Presentations of torsion are not necessarily classic, particularly early on.

- Where appropriate, emergency surgery may be indicated to attempt salvage of testicles.

- Long-term sequelae of the absence of testicular function are important and require long-term management, and include infertility, hypogonadism and arrested development/puberty. shrunken and firm to palpation suggesting natural involution was ongoing.

Finally, it is important to follow up these patients (particularly in cases of bilateral torsion as here as this patient will have no testicular function whatsoever) to review their need for hormonal replacement and future development.

Correction notice This article has been corrected since it was published. One of the corresponding author's email addresses has been removed. The patient's haemoglobin value has also been corrected to $228 \mathrm{~g} / \mathrm{L}$.

Acknowledgements The authors would like to thank the parents of the patient involved in this article for their kind assistance with its development and for their consent to publication.

Contributors MJHC and SC collected patient review and information. MJHC prepared manuscript with contributions from SC (including abstract and information regarding radiology findings). JA provided radiology input. DGB supervised all discussions and performance.

Competing interests None declared.

Patient consent Obtained.

Provenance and peer review Not commissioned; externally peer reviewed.

(c) BMJ Publishing Group Ltd (unless otherwise stated in the text of the article) 2018. All rights reserved. No commercial use is permitted unless otherwise expressly granted.

\section{REFERENCES}

1 John CM, Kooner G, Mathew DE, et al. Neonatal testicular torsion--a lost cause? Acta Paediatr 2008:97:502-4.

2 Riaz-Ul-Haq M, Mahdi DE, Elhassan EU. Neonatal testicular torsion; a review article. Iran J Pediatr 2012:22:281-9.

3 Brereton RJ, Manley S. Acute scrotal pathology in boys. Z Kinderchir Grenzgeb 1980;29:343-57. Cited in: Riaz-Ul-Haq M, Mahdi DEA, et al. Neonatal testicular torsion; a review article. Iranian Journal of Paediatrics 2012;22(3): 281-289.

4 Das $S$, Singer A. Controversies of perinatal torsion of the spermatic cord: a review, survey and recommendations. J Urol 1990;143:231-3.

5 Nandi B, Murphy FL, et al. Neonatal testicular torsion: a systematic literature review. Pediatr Surg Int 2011:27:1037-40.

6 Dunne PJ, O'Loughlin BS. Testicular torsion; time is the enemy. ANZ Journal of Surgery 2000:70:441-2.

7 Weber DM, Rösslein R, Fliegel C, et al. Color Doppler sonography in the diagnosis of acute scrotum in boys. Eur J Pediatr Surg 2000;10:235-41.

8 Baglaj M, Carachi R. Neonatal bilateral testicular torsion: a plea for emergency exploration. J Urol 2007;177:2296-9.

9 Granger J, Brownlee EM, Cundy TP, et al. Bilateral perinatal testicular torsion: successful salvage supports emergency surgery. BMJ Case Rep 2016. doi:10.1136/ bcr-2016-216020. [Epub ahead of print 15 Jun 2016].

10 Callewaert PR, Van Kerrebroeck P. New insights into perinatal testicular torsion. Eur J Pediatr 2010;169:705-12 https://link.springer.com/article/.

11 Pinto KJ, Noe HN, Jerkins GR. Management of neonatal testicular torsion. J Urol 1997;158:1196-7.

12 Brandt MT, Sheldon CA, Wacksman J, et al. Prenatal testicular torsion: principles of management. J Urol 1992;147:670-2.

13 Kaye JD, Levitt SB, Friedman SC, et al. Neonatal torsion: a 14-year experience and proposed algorithm for management. J Urol 2008;179:2377-83.

14 Cuervo JL, Grillo A, Vecchiarelli C, et al. Perinatal testicular torsion: a unique strategy. J Pediatr Surg 2007;42:699-703.

15 Yerkes EB, Robertson FM, Gitlin J, et al. Management of perinatal torsion: today, tomorrow or never? J Urol 2005;174:1579-83. 
Rare disease

Copyright 2018 BMJ Publishing Group. All rights reserved. For permission to reuse any of this content visit http://group.bmj.com/group/rights-licensing/permissions.

BMJ Case Report Fellows may re-use this article for personal use and teaching without any further permission.

Become a Fellow of BMJ Case Reports today and you can:

- Submit as many cases as you like

- Enjoy fast sympathetic peer review and rapid publication of accepted articles

- Access all the published articles

- Re-use any of the published material for personal use and teaching without further permission

For information on Institutional Fellowships contact consortiasales@bmjgroup.com

Visit casereports.bmj.com for more articles like this and to become a Fellow 